\title{
Constatação de Graphiola phoenicis em tamareira no estado de São Paulo
}

\author{
Olga Maria Ripinskas Russomanno ${ }^{1}$, Pedro Carlos Kruppa ${ }^{1}$, Michele Pereira Silva $^{1,3}$, Leila Nakati Coutinho ${ }^{2}$
}

${ }^{1}$ Centro de Pesquisa e Desenvolvimento de Sanidade Vegetal, Instituto Biológico, 04014-002, São Paulo, SP, Brasil. ; ${ }^{2}$ Instituto de Botânica, 04301-012, São Paulo, SP, Brasil; ${ }^{3}$ Bolsista de Iniciação Científica PIBIC/CNPq/IB

Autor para correspondência: Olga Maria Ripinskas Russomanno (russomano@biologico.sp.gov.br)

Data de chegada: 20/11/2008. Aceito para publicação em: 19/06/2009.

As palmeiras (família Arecaceae) são plantas comumente utilizadas no paisagismo na formação de jardins, isoladas ou compondo arranjos ornamentais com outras espécies vegetais. Nos últimos anos, o mercado dessas plantas cresceu consideravelmente, sendo cultivadas as mais diferentes espécies por viveiristas e produtores. Como todas as demais plantas, as palmeiras também são atacadas por fungos fitopatogênicos, causando danos consideráveis tanto à produção de mudas quanto a plantas adultas de médio e grande porte.

No final de 2007, folhas de palmeira tamareira (Phoenix dactylifera), procedentes do município de Campo Limpo Paulista, SP, foram enviadas ao Centro de Pesquisa e Desenvolvimento de Sanidade Vegetal, Instituto Biológico, para exames micológicos. Os sintomas iniciais da doença caracterizavam-se por pequenas manchas amarelas, localizadas nas duas faces da lâmina foliar. Com a coalescência das lesões, as manchas tornavam-se necróticas e sobre as mesmas emergiam as estruturas reprodutivas do fungo (soros), as quais se assemelhavam, quando visualizadas a olho nu, a um ataque de insetos, lembrando restos de suas carapaças ou fezes deixadas sobre as folhas (Figura 1A e 1B). O material foi colocado em câmara úmida, com temperatura de $24{ }^{\circ} \mathrm{C}$, sendo examinado após três dias, sob microscopia óptica e estereoscópica. Esses exames possibilitaram a visualização de uma exsudação de pulverulentos esporos amarelos, intercalares com feixes de hifas, emergindo do interior de soros. Essas hifas estendiam-se por cerca de 1,0-2,0 mm para fora dos soros (Figura 1C). De acordo com as características do fungo e com auxílio de literatura especializada (Djerbi, M. Diseases of the palm (Phoenix dactylifera). Regional Project for Palm \& Dates Research Centre in the Near East \& North África. Baghdad, Iraq:FAO. 1983; Simone, G.W. Graphiola leaf spot (false smut). In: M. L. Elliot; T.K. Broschat (Eds.). Diseases and disorders of ornamental palms. Minnesota: American Phytopathological Society, 1993. p. 14-16), o mesmo foi identificado como Graphiola phoenicis (Moug.) Poit. 1824, sinonímia Phacidium phoenicis Moug. Ex Fr., 1823. Esse fungo é um Basidiomycota responsável pela doença conhecida como "mancha foliar de grafiola" ou "falso carvão" das palmeiras. Acomete ampla gama de plantas da família Arecaceae, principalmente o gênero Phoenix, e encontra-se disseminado por diversas regiões do mundo. A alta umidade do ambiente é fator preponderante para o desenvolvimento do fungo. No Brasil, $G$. phoenicis foi constatado em $P$. dactylifera nos estados de Pernambuco (Lima, M.F. Fitopatologia Brasileira, v. 20, p. 306, 1995; Lima, M.F. Plant Disease, v. 80, p. 823, 1996) e Espírito

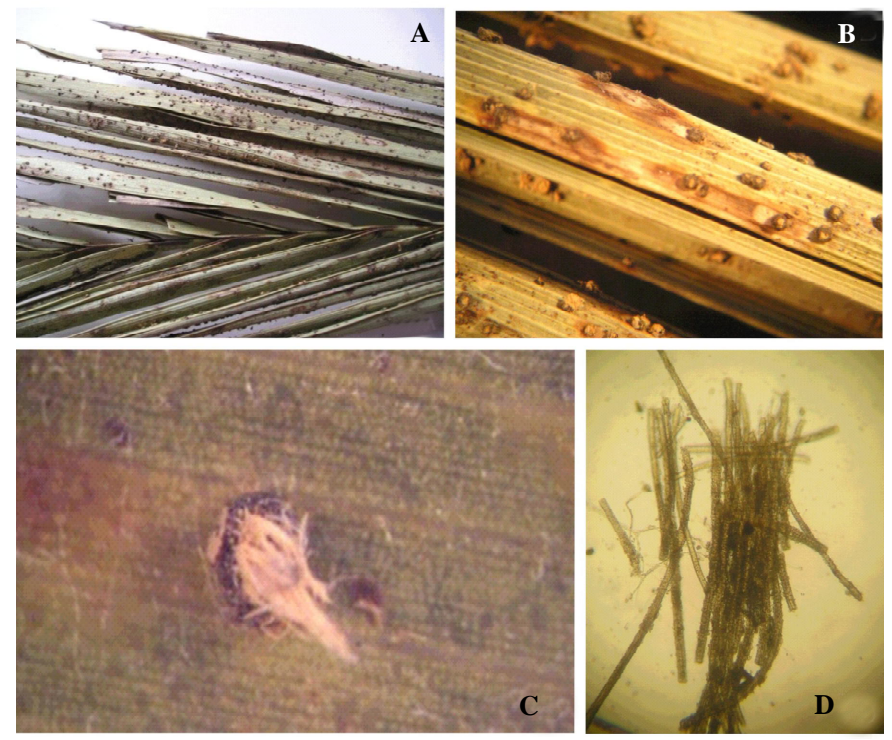

Figura 1. Folha de palmeira Phoenix dactylifera mostrando os soros (estruturas reprodutivas) do fungo Graphiola phoenicis (A), detalhe do soro liberando os feixes de hifas (B), detalhe dos soros, mostrando a liberação das hifas e esporos (C) e feixe de hifas em microscopia óptica (40X) (D).

Santo (Câmara, M.P.S.; Dianese, J.C.; Ventura, J.A. Fitopatologia Brasileira, v. 20, p. 293, 1995). As características do fungo, distribuição geográfica, hospedeiros, sinais, sintomatologia, etiologia e controle, foram descritos por Russomanno \& Kruppa (Russomanno, O.M.R.; Kruppa, P.C. Mancha foliar de grafiola. Documento Técnico no. 2, p. 1-8, 2008. Disponível em www.biologico.sp.gov.br ). Em São Paulo, através de levantamento realizado no Herbário Fitopatológico do Laboratório de Micologia Fitopatológica do Instituto Biológico, verificou-se a existência de cinco exsicatas de $P$. dactylifera parasitadas por G. phoenicis. Essas exsicatas datam de 1932, 1936, 1938, 1951 e 1955, sendo os materiais provenientes, respectivamente, de Sorocaba (SP), Nova Odessa (SP), Bonfim (BA), Cruz das Almas (BA) e Recife (PE). Entretanto, nenhuma dessas constatações foi publicada, o que leva os autores a enunciar que, no estado de São Paulo, esta é a primeira publicação da ocorrência de G. phoenicis sobre P. dactylifera. 